\title{
Evidence-based Chronic Ulcer Care and Lower Limb Outcomes among Pacific Northwest Veterans
}

\author{
Mahsa Karavan \\ A thesis submitted in partial fulfillment of the requirements for the degree of \\ Master of Public Health \\ University of Washington \\ 2013
}

Committee:

Gayle E. Reiber

John Olerud

Program Authorized to Offer Degree:

School of Public Health- Department of Health Services 
CCopyright 2013

Mahsa karavan 
University of Washington

\begin{abstract}
Mahsa Karavan

Chair of the Supervisory Committee:

Professor Gayle E. Reiber

Department of Health Services
\end{abstract}

Evidence-based Chronic Ulcer Care and Lower Limb Outcomes among Pacific Northwest Veterans

Introduction: Chronic lower limb ulcers (LLU) impact morbidity, mortality, and quality of life. Although evidence-based (EB) care guidelines exist for most ulcer types, the literature on the impact of ulcer care component on time to healing is sparse. The purpose of this study is to investigate the frequency EB care components are performed and their impact on ulcer outcomes among rural and urban Veterans in the Pacific Northwest. As part of EB ulcer care we also assess relationship between early specialty care and ulcer healing.

Methods: This is a retrospective medical records review of Veterans with venous, arterial, and diabetic foot ulcers (DFU/Neuropathic) identified by ICD-9 codes. Components of EB ulcer care for each ulcer type were identified from EB guidelines. Venous ulcers: infection assessment, sharp debridement, moist wound healing, and edema assessment and treatment. Arterial ulcers: infection and ischemia assessment, and vascular surgery consultation within 30 days. DFU/neuropathic ulcers: infection and ischemia assessment, moist wound healing, sharp debridement, and offloading. A separate Cox model was created for each of the three ulcer types with days to healing as outcome, and included health history variables and EB ulcer care components. A Cox model for access to specialty care within 30 days 
of presentation for ulcer care included health-history variables without adjusting for ulcer care components.

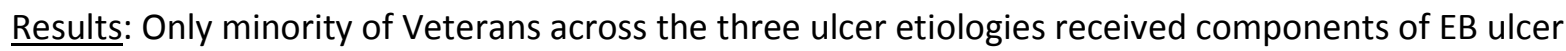
care in at least $80 \%$ of visits. Among those with venous ulcers, there was a significantly higher chance of healing if edema and infection assessment were performed on at least $80 \%$ of visits $(H R=3.20, p=0.009$ and $\mathrm{HR}=3.54, \mathrm{p}=0.006$, respectively). Edema treatment was not associated with ulcer outcome. None of the ulcer care components considered for arterial ulcer significantly impacted time to healing. Among DFU/Neuropathic ulcers the chance of healing was 2.5 time higher if debridement was done at $80 \%$ of visits ( $p=0.03)$, and 2 times higher if ischemia was assessed at first visit $(p=0.045)$. Access to specialty care within 30 days of ulcer onset was not associated with healing.

Discussion: We found that Veterans in the Pacific Northwest did not uniformly receive EB ulcer care. When component of ulcer care were performed at satisfactory levels, only a few significantly impacted ulcer time to healing. Small sample size and wide variation in ulcer care may have contributed to some of the null findings observed among ulcer care components and outcome. Rural and urban clinicians need to address those components of ulcer care associated with improved outcomes. 


\section{Table of Contents}

Introduction $\quad \mathbf{8}$

Methods 99

Results

\begin{tabular}{ll} 
Discussion & 15 \\
\hline
\end{tabular}

Conclusion and future recommendation 24

Bibliography

Appendix 33

Appendix A: Map of VISN 20 with 8 parent facilities 34

Appendix B: Methods for assigning ulcer etiology 35

Appendix C: Edema/ischemia assessment and presence 37

Appendix D: Moist wound healing 39

Appendix E: Parent study chart abstraction form 40 


\section{List of Tables}

Table 1. Chronic ulcer definition and evidence-based ulcer care components......................................19

Table 2. Demographic and health characteristics of Veterans with chronic lower limb ulcers in VISN 20

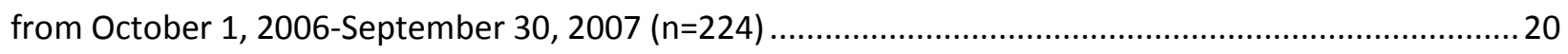

Table 3. Chronic ulcer frequency and outcomes in VISN 20 Veterans at 12 months follow-up.................22

Table 4. Chronic ulcer healing and evidence-based ulcer care in VISN 20 Veterans.................................23

Table 5. Receipt of specialty care by one month following presentation and time to healing for chronic

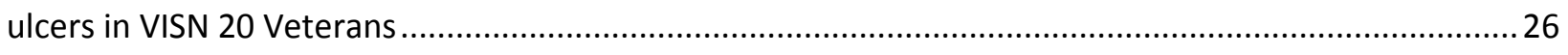

Table 6. Proportion of wound care visits by provider type in VA VISN 20 Veterans ................................27

Table 7. Provider type evidence-based chronic ulcer care in VISN 20 Veterans ......................................28

Table 8. Diabetes control and chronic ulcer time to healing in VISN 20 Veterans with diabetes ..............29 


\section{Acknowledgements}

I would like to express my deepest gratitude to Dr. Gayle Reiber, my mentor and thesis committee chair, for her endless support, encouragement, and enthusiasm throughout the past year. Through her selfless dedication and care she has inspired a passion in me for personal growth and public health research. I would like to extend my appreciation to Dr. John Olerud, member of my thesis committee, for his advice, support, and guidance. Dr. Olerud's well-experienced clinical perspective on chronic ulcer care was invaluable to my thesis. 


\section{Introduction}

Chronic lower limb ulcers (LLU) occur most commonly as result of complications of venous hypertension, arterial insufficiency, and diabetes. Evidence-based (EB) guidelines for etiology-specific

ulcer care exist. ${ }^{1-5}$ Yet in both specialty and general settings, the delivery of evidence-based ulcer care is not uniform. Reasons include the broad clinical spectrum of chronic ulcers, contributions from other medical comorbidities, the many health care disciplines performing ulcer care, the time- and laborintensive care required to achieve healing, and the poor coordination and hand offs for care among health care providers in different healthcare systems caring for the same patient.

Evidence-based ulcer care is associated with improvements in chronic venous ulcer outcomes. A recent study by Olsen et al. ${ }^{6}$ assessed the impact of EB ulcer care on healing of venous ulcers which account for over $70 \%$ of all LLUs ${ }^{7}$. They reported the likelihood of venous ulcer healing among Veterans increased when compression therapy, sharp debridement, and moist wound healing were all provided in at least $80 \%$ of visits ( $R R=2.52 ; 95 \%$ confidence interval $[\mathrm{Cl}]: 1.53-4.16)$. Compression therapy and moist wound healing both independently increased the likelihood of healing when performed at $\geq 80 \%$ of visits, however debridement alone was not significantly associated with venous ulcer healing. ${ }^{6}$

Arterial insufficiency, the second most common cause of LLUs, comprises $10-30 \%$ of all chronic LLUs $^{7}$. Diabetic LLUs comprise $15-25 \%$ of ulcers ${ }^{7}$ and have the worst prognosis and the highest amputation rate. ${ }^{5,8}$ Since the prevalence of diabetes is higher among Veterans (24\%) compared to the general population (8\%), they experience higher rates of diabetes-related ulcers and amputations making this a priority clinical problem. ${ }^{9}$

Although individual components of EB ulcer care have been associated with improved wound healing for venous, arterial, and DFU/neuropathic ulcers (Table 1), Olsen et al. was the only study we found on the impact of guideline concordance on outcomes. In addition despite existence of EB 
guidelines, there is still a significant practice gap in the evidence-based diagnosis and treatment of these ulcers $^{10}$. EB guidelines recommend referral to specialized care as part of a multidisciplinary provider team to achieve optimal outcomes for ulcers extending 4-12 weeks ${ }^{10-13}$. A correlation between ulcer duration at the time of first specialty evaluation and the time to subsequent healing was established by two studies ${ }^{14,15}$, suggesting that timely referral to specialty care could be an important part of good ulcer care.

The VA recognizes the impact of chronic lower limb ulcers on function, quality of life, and healthcare cost. VHA developed multidisciplinary programs such as High Risk Foot Clinics and Preservation-Amputation Care and Treatment (PACT) teams, to prevent or delay amputations through proactive identification of patients at risk of limb loss. Therefore the purpose of this study is to investigate the frequency with which components of EB ulcer care are performed, and their impact on LLU outcomes among Veterans. We also assessed the impact of early specialty care utilization on ulcer healing among Veterans with chronic LLUs. We hypothesized that Veterans receiving EB ulcer care and those with earlier access to specialty wound care would experience improved ulcer outcomes.

\section{Methods}

Subject Selection: This study, a retrospective medical records review, was conducted in the VA's Northwest Health Network (VISN 20), which consisted of 8 parent facilities and 23 community based outpatient clinics (CBOCs) during the study period. This project was approved by IRBs at both the VA Puget Sound Health Care System and the University of Washington. A set of high-probability ICD-9 codes $(n=46)$, based on previous studies, was used to identify potential subjects with at least one incident LLU between October 1, 2006 and September 30, 2007. ${ }^{16}$ The parent study, examining differences between rural and urban Veterans, screened a randomized list of potential subjects until 160 rural and 160 urban Veterans who met inclusion criteria were identified. All 320 Veterans had a chronic LLU, defined as an 
open wound that did not heal within 30 days of the first VA treatment visit, or a LLU that necessitated amputation prior to 30 days of treatment. Ulcers were associated with at least two VA inpatient or outpatient encounters. Veterans receiving palliative care during study period (no expectation of ulcer healing), and those who died within 30 days of ulcer onset were excluded. Ulcer etiology was determined (MK) from progress notes, ulcer specific ICD-9 codes, diagnostic imaging and procedures. All ulcers were categorized as venous, arterial, DFU/neuropathic, pressure ulcers, infectious, burns, blistering skin diseases, and unknown etiology ulcers. From the 320 Veterans, we selected those presenting with venous, arterial, and DFU/neuropathic ulcers for inclusion in the study. Regardless of diabetes status, foot ulcers in Veterans with severe peripheral occlusive disease as determined by vascular surgery consultation, or LE arterial blockage on imaging and ABI less than 0.8 , were classified as arterial ulcers as treatment of severe ischemic ulcer does not include debridement and moist wound healing. ${ }^{1}$

Data Collection: We abstracted medical records from the VA's Computerized Patient Record System (CPRS) to collect demographic, health-history, and ulcer care-related variables from October 1, 2006 to September 30, 2007. Chronic ulcer was defined as wounds that do not heal completely after receiving standard medical treatment for 30 days. ${ }^{17}$ Ulcer related progress notes were reviewed for ulcer care components and outcomes. The primary outcome was time to healing and healing was defined as the complete re-epithelialization of the ulcer with documented maintenance of skin integrity for at least 30 days. The following elements were recorded for every visit: provider type, provider assessment for ulcer infection, sharp debridement, offloading implementation, moist wound healing environment, edema assessment, edema control, LL ischemia assessment, presence/absence of LL ischemia, antibiotic prescription for systemic and/or wound infection, imaging and surgical procedures, global assessment, and follow-up planning. Provider types included vascular surgeon, other specialty (dermatology, general surgery, orthopedics), primary care, podiatry, urgent care, wound-care provider (licensed wound care 
professional including nurse practitioners and physician assistants), and general nurse practitioners.

Table 1 provides detail on definition of each element and the supporting evidence.

Health history was recorded at baseline (first ulcer treatment visit) and was based on the diagnoses listed in the medical record or noted by the provider during the exam. All conditions were classified as present or absence except diabetes: diabetes presence and control was included as a threelevel variable: no diabetes, controlled diabetes, and uncontrolled diabetes. $\mathrm{HbA} 1 \mathrm{C}$ levels were used to define diabetes control; values above 7.0 were considered uncontrolled while those equal to and lower than 7.0 were considered to be controlled. Rural residence was defined using the VA's classification system, which considers United States Census Bureau-defined Urbanized Areas (Census blocks or block groups with a minimum density of 1,000 people per square mile) and surrounding blocks with a minimum density of 500 people per square mile to be urban. Any non-urban area is considered rural. ${ }^{18}$

Ulcer outcomes: We followed Veterans' first incident ulcer from the first VA visit up to one year for the following outcomes: healed, amputated, died with active ulcer, unresolved ulcer at end of observation period, and lost to follow-up. If an ulcer did not heal within one year of first treatment, the outcome was considered 'unresolved'. If the ulcer resolution date was not stated in the chart but the ulcer was on a healing trajectory (e.g., decreasing size, evidence of granulation), the healed date was estimated as the date of the next visit when the ulcer was no longer mentioned, if this visit was within 6 months of the preceding ulcer treatment visit, or as the mid-point of the most recent visit and last visit if more than 6 months elapsed.

Statistical analysis: Cox models were used to assess the impact of ulcer care components and early specialty care on time to healing of LLUs, with days to healing as the dependent variable and the outcome. A hazard ratio above 1 implies improved chance of healing. A separate Cox model was created for each of the three ulcer types. All models included rural status; age at first study ulcer presentation; 
smoking status; and history of coronary artery disease (CAD), lower limb ulcer, lower limb amputation, and moderate to severe renal disease. The venous ulcer Cox model adjusted for binary indicators of whether the following elements were performed in at least $80 \%$ of visits: edema assessment, moist wound healing, and infection assessment. The model also included continuous variable for percent of visits when edema was present and was treated. Since there were too few visits where edema was both assessed by the provider and treated, we chose not to collapse this into a binary indicator. The venous ulcer model also adjusted for history of PVD and diabetes presence/control.

The Cox model for Veterans with arterial ulcers included binary indicators of whether ischemia was assessed at the first visit, whether infection was assessed in at least $80 \%$ of visits, and if a vascular surgery consult occurred within 30 days of ulcer presentation. The arterial ulcer model also included adjustment for diabetes presence/control. We did not adjust for history of PVD in this model since most of the Veterans with arterial ulcers (95\%) had PVD at baseline.

The Cox model for Veterans with DFU/neuropathic ulcers included binary indicators of whether the following elements were performed in at least $80 \%$ of visits: sharp debridement, moist wound healing, infection assessment, and offloading. The model included adjustment for history of PVD. We did not adjusted for diabetes diagnosis in this model because the majority of Veterans in this group (about 90\%) had diabetes.

To describe patterns of care and specialty care utilization, we calculated the proportion of visits when Veterans with each ulcer type saw a specialist, primary care provider, urgent care, wound care provider, or general nurse. In order to assess whether utilization of specialty care among Veterans with chronic LLUs influenced healing, we created four additional etiology-specific Cox models. The primary exposure in each model was a specialty care visit within one month of the first ulcer-related visit. For venous ulcers, specialties of interest were vascular surgery, orthopedics, and dermatology. For arterial 
ulcers, the specialty of interest was vascular surgery. For DFU/neuropathic ulcers the specialties of interest were podiatry, vascular surgery, orthopedics, and dermatology. Given the differences in training and practices, we created two separate models for DFU/neuropathic ulcers: one assessing the influence of podiatry on ulcer healing and the second assessing the influence of the vascular surgery, orthopedics, and dermatology on ulcer healing. These models did not adjust for the ulcer care components.

Data management was conducted using SAS 9.2 (Cary, NC) and statistical analyses were conducted in STATA 12.1 (College Station, TX). For each model, we tested to see if the proportional hazards assumptions for the Cox model were satisfied.

We used the Multiple Imputation by Chained Equations (MICE) method to impute missing values, specifically: 6 missing BMI, 1 history of lower leg ulcer, and 12 history of smoking values. Factors used to predict these values were history of diabetes, PVD, CAD, age at ulcer onset, previous lower limb amputation, congestive heart failure, and renal disease. We used 10 simulated datasets to impute the data.

\section{Results}

There were 224 Veterans from the parent study who had venous, arterial, or DFU/neuropathic ulcer etiology and were included in this study [Table2]. There were 78 venous, 57 arterial, and 98 DFU/Neuropathic. Most Veterans were white males in their mid to late 60's. Their health history was similar across ulcer groups with the exception of higher prevalence of diabetes and metabolic syndrome among those with DFU/neuropathic ulcers, higher prevalence of PVD, CAD, and smoking in arterial ulcer group, and higher prevalence of venous insufficiency among those with venous ulcers [Table 2]. Proportion of Veterans with venous, arterial, and DFU/neuropathic ulcers who had history of diabetes were 47,70 , and $89 \%$ respectively [Table 2 ]. 
Ulcer Outcomes: Nine Veterans had ulcers with two etiologies; of these 6 were mixed arterialvenous, and 3 were DFU-arterial ulcers [Table 3]. The highest percentage of healed ulcers was in Veterans with diabetes followed by venous ulcers and finally arterial ulcers (75\%, $72 \%$ and 53\% respectively). The highest proportion of amputations occurred in Veterans with arterial ulcers (23\%) followed by Veterans with DFU/Neuropathic Ulcers (15\%) and Veterans with venous ulcers (1\%). The highest proportion of deaths was in the arterial ulcer group (12\%). After one-year follow-up the highest proportion of unhealed ulcers was in the venous ulcer group (18\%).

Components of evidence-based ulcer care and ulcer healing: Among Veterans with a venous ulcer, $20 \%$ had edema assessment or moist wound healing elements in at least $80 \%$ of their visits. However sharp debridement was not performed on at least $80 \%$ of visits for any Veteran with venous ulcer and therefore this variable was excluded from venous ulcer analysis. There was a significantly higher chance of healing among Veterans receiving edema assessment on at least $80 \%$ of visits $(\mathrm{HR}=3.20,95 \% \mathrm{Cl}: 1.34-7.66, \mathrm{p}=0.009)$ and infection assessment on at least $80 \%$ of visits $(\mathrm{HR}=3.54,95 \%$ Cl 1.42-8.79, $p=0.006$ ) (Table4).

Among Veterans with arterial ulcers, 32\% had infection assessment in at least $80 \%$ of visits, $56 \%$ had ischemia assessment on the first visit, and $39 \%$ had a vascular surgery evaluation within 30 days of ulcer presentation. All arterial ulcer care HRs were above 1 but not statistically significant [Table 4].

Among Veterans with DFU/neuropathic ulcers, $19 \%$ has sharp debridement on at least $80 \%$ of visits, $19 \%$ had moist wound healing on at least $80 \%$ of visits, $50 \%$ had infection assessment on at least $80 \%$ of visits, $13 \%$ had offloading on at least $80 \%$ of visits, and $50 \%$ received an ischemia assessment at their first visit. The chance of healing for Veterans having sharp debridement in at least $80 \%$ of visits was 2.5 times the chance of healing for those receiving this component on less than $80 \%$ of visits $(95 \% \mathrm{Cl}$ :

1.10- $5.80 p=0.03$ ). Ischemia assessment at the first visit doubled the likelihood of ulcer healing ( $H R=2.0$, 
95\% Cl: 1.0-3.9, $\mathrm{p}=0.045)$. The remaining three wound care components, moist wound healing, infection assessment, and offloading, were not significantly associated with ulcer healing (Table 4).

Professional care encounters and impact on LLU healing: A specialty care encounter within 30 days of ulcer onset was not significantly associated with improved ulcer healing for Veterans with any ulcer etiology (data not show).

General nurses and wound-care providers performed the highest proportion of venous ulcer visits (39\% and 37\%, respectively). Specialty care combination of orthopedics, dermatology, and general surgery, followed by general nursing, performed the highest proportion of arterial ulcer care visits. Podiatrist performed the highest proportion of DFU/neuropathic ulcer visits (43\%), followed by general nursing (29\%).

\section{Discussion}

The major finding of this study is that components of EB ulcer care are not uniformly performed on at least $80 \%$ of visits for the majority of VISN 20 Veterans with chronic LLU. EB ulcer care guidelines do not currently specify the frequencies for performing components of EB ulcer care. We set $80 \%$ of visits as a satisfactory threshold for ulcer care components based on a recent study by Olsen et al. on venous ulcer healing, as well as two prior studies examining guideline-concordant care in heart disease and depression. ${ }^{6,19,20}$ Unlike Olsen et al. we found that very few Veterans received combination of all EB ulcer care components in at least $80 \%$ of their visits. Therefore we were unable to analyze the impact of all EB ulcer components performed in at least $80 \%$ of visits on ulcer healing. This may reflect the differences in setting and Veteran populations between the two studies. While Olsen et al. studied mainly urban Veterans receiving care at two multidisciplinary, tertiary care centers, our study included Veterans receiving ulcer care across VISN 20 rural and urban clinics.

As hypothesized, we observed that both edema and infection assessment on at least $80 \%$ of visits significantly improved the chance of healing among Veterans with venous ulcers. We were unable 
to assess the association between debridement performance and healing since debridement of venous ulcers was done so infrequently. Sharp debridement had the greatest impact on DFU/neuropathic ulcer healing when performed on at least $80 \%$ of visits; this was followed by ischemia assessment at first visit that also significantly improved healing time. These findings emphasize the importance of sharp debridement and ischemia assessment in the management of DFU/neuropathic ulcers.

Increasing the proportion of visits where edema was treated with compression therapy had no effect on venous ulcer healing $(H R=1.00,95 \% \mathrm{Cl}: 0.99-1.01, p=0.680)$. Two reasons for his could be first the lack of power to detect this relationship due to the small sample size and second, poor patient compliance with compression therapy. A large study on patient compliance with compression therapy reported that $63 \%$ of patients with chronic venous disease did not use compression stockings at all, and only $21 \%$ used them on a daily basis. ${ }^{21}$ The study estimated that stockings were unusable in about a quarter of patients because of general health or limb conditions, they were ineffective despite compliance in a third of patients, and in the remainder, major cause of treatment failure was noncompliance. $^{21}$

Dressings enhancing moist wound healing for at least $80 \%$ of visits in both venous and DFU/neuropathic ulcers was suggestive of decreased chance of healing, though results were not statistically significant (Table4). This trend is challenging to explain considering previous literature suggesting moist wound environment with occlusive dressings improves chronic wound healing by stimulating granulation tissue, and inducing autolytic debridement. ${ }^{2,3,22,23}$ However, the possibility of ulcer infection is the most significant disadvantage of moist wound healing, along with risk of inducing an exudative phase in an otherwise dry ulcer. ${ }^{24}$ Therefore it is possible that moist wound healing in fact did have negative effect on healing.

A limitation of this study is our definition of debridement, which was sharp debridement and excluded enzymatic and mechanical methods. ${ }^{2,3,25}$ These additional means of debridement were 
included in Olsen et al. and could help explain why we did not see higher levels of debridement for venous ulcers. Also, retrospective chart review studies are subject to failure to record provided treatments. It is possible that components of EBUC collected in this study could be artificially low for this reason. This weakness can be improved by future prospective studies where providers and staff uniformly complete comprehensive notes on ulcer care components performed during each visit. Since sample sizes within ulcer groups were small, future studies with larger samples may provide more definitive answers on the effect of ulcer care components on chronic ulcer outcomes. Another limitation of this study was our inability to adjust for ulcer size and depth at the presentation due to frequent missing values in the medical records. This could have potentially confounded the relationship between EB ulcer care and time to healing. ${ }^{14}$ Although we do not have a strong reason to believe that ulcer size at presentation was dissimilar between Veterans who did and did not receive components of EB ulcer care, if such an association exists, it could impact results. The size and severity of ulcers may also contribute to the unexpected results of the impact of specialty care on ulcer healing. If Veterans with larger and more complex ulcers are more likely to be referred to specialty care, their poorer outcomes compared to less severe ulcers can confound the true impact of specialty care on healing.

In conclusion we found that components of EB ulcer care are not uniformly performed on at least $80 \%$ of visits for the majority of VISN 20 Veterans with chronic LLU; and when performed at this threshold, only few components were significantly associated with improved time to healing. In our study, most of the ulcer care components were performed in a higher proportion of visits by vascular surgery and other specialties combined (dermatology, general surgery, orthopedics), followed by podiatry and wound-care nurses. Rural Veterans have reduced access to high-specialty providers, which could impact the quality of healthcare they receive ${ }^{26}$. In our literature search we did not find chronic ulcer care studies that actively recruited rural residence. Considering that Veteran enrollees in the VHA are $41 \%$ rural ${ }^{27}$, the result of our study comprising of $50 \%$ rural Veterans is unique in that it reflects 
access to chronic ulcer care received by a representative sample of Veterans in the VA. Further studies are needed to compare the ulcer care components among rural and urban Veterans and to shed light on the possible impact of rurality on evidence-based ulcer care.

\section{Acknowledgements}

Acknowledgements: This work was funded by the US Department of Veterans Affairs, Office of Rural Health Services, VA Health Services Research and Development, and the Career Scientist Award of Dr. Gayle Reiber (RCS 98-353). The views expressed in this article do not necessarily reflect those of the Department of Veterans Affairs or the United States Government.

\section{Conflict of Interest}

The authors have no conflict of interest to declare. 
Table 1. Chronic ulcer definition and evidence-based ulcer care components

\begin{tabular}{|c|c|c|}
\hline $\begin{array}{l}\text { Ulcer Etiology and } \\
\text { Evidence-based } \\
\text { references }\end{array}$ & Evidence-based ulcer care components & Ulcer etiology definition \\
\hline $\begin{array}{l}\text { Venous } \\
1-{ }^{3,6,13,28-33} \\
\text { 2- }^{3,22,29,32-34} \\
3^{3,35,36}\end{array}$ & $\begin{array}{l}\text { 1- Compression therapy: edema control could be } \\
\text { achieved through the use of compression stockings } \\
\text { or dressings or by elevating the lower extremities } \\
\text { 2- Moist wound healing: application of dressing that } \\
\text { maintains moist wound environment. All major } \\
\text { moist dressings were considered, for example } \\
\text { Duoderm, Hydrosorb, Aquaphore, hydrocolloid and } \\
\text { Alginate dressing, Tegaderm, Allevyn, Vaseline } \\
\text { gauze, etc. } \\
\text { 3- Sharp debridement: remove all necrotic or } \\
\text { devitalized tis- sue by surgical and mechanical } \\
\text { means (this study does not include other types of } \\
\text { debridement) }\end{array}$ & $\begin{array}{l}\text { Ulcers due to venous } \\
\text { incompetence most } \\
\text { commonly occur above } \\
\text { the medial or lateral } \\
\text { malleoli }^{31}\end{array}$ \\
\hline $\begin{array}{l}\text { Arterial } \\
1 \text { and } 2-{ }^{1,37-40}\end{array}$ & $\begin{array}{l}\text { 1- Assess ischemia (palpable pedal pulses, } A B I>0.8 \text {, } \\
\text { normal Doppler waveform, normal color duplex } \\
\text { ultrasound, toe-brachial index }>0.7 \text { ) } \\
\text { 2- Evaluation for revascularization: in this study a } \\
\text { vascular surgery encounter within } 30 \text { days of ulcer } \\
\text { onset was considered a component of ulcer care }\end{array}$ & $\begin{array}{l}\text { Caused by poor perfusion } \\
\text { to the lower limbs and } \\
\text { often affect the toes or } \\
\text { shin or occurs over } \\
\text { pressure points } 31 \\
\text { Findings include absent } \\
\text { pedal pulses, } \mathrm{ABI}<0.9 \\
\text { and/or MRI/ultrasound } \\
\text { evidence of arterial } \\
\text { blockage }\end{array}$ \\
\hline $\begin{array}{l}\text { DFU/Neuropathic } \\
\text { 1- } 2,37-40 \\
\text { 2- }^{2,4,41} \\
\text { 3- }^{2,22} \\
\text { - } 2,35,42,43^{2}\end{array}$ & $\begin{array}{l}\text { 1- Assess ischemia (palpable pedal pulses, } \mathrm{ABI}>0.8 \text {, } \\
\text { normal Doppler waveform, normal color duplex } \\
\text { ultrasound, toe-brachial index }>0.7 \text { ) } \\
\text { 2- Offloading: crutches, walkers, wheelchairs, } \\
\text { custom shoes, depth shoes, shoe modifications, } \\
\text { custom inserts, custom relief orthotic walkers } \\
\text { (CROW), diabetic boots, forefoot and heel relief } \\
\text { shoes, and total contact casts } \\
\text { 3- Moist wound healing: see above for venous } \\
\text { ulcers } \\
\text { 4- Sharp debridement: see above for venous ulcers }\end{array}$ & $\begin{array}{l}\text { Usually occurs on plantar } \\
\text { aspect of feet or over } \\
\text { pressure points in } \\
\text { patients with diabetes } \\
\text { and neurologic disorders } \\
31\end{array}$ \\
\hline $\begin{array}{l}\text { All chronic ulcers } \\
1-3,44,45\end{array}$ & $\begin{array}{l}\text { Infection assessment: ulcer examination for signs of } \\
\text { invasive bacterial infection of soft tissue or bone }\end{array}$ & \\
\hline
\end{tabular}


Table 2. Demographic and health characteristics of Veterans with chronic lower limb ulcers in VISN 20 from October 1, 2006-September 30, 2007 ( $n=224)$

\begin{tabular}{|c|c|c|c|c|c|}
\hline Variable & Category & Measure & $\begin{array}{l}\text { Veterans with } \\
\text { venous ulcer } \\
\quad(n=57)^{*}\end{array}$ & $\begin{array}{l}\text { Veterans with } \\
\text { arterial ulcer } \\
\qquad(n=78)^{*}\end{array}$ & $\begin{array}{l}\text { Veterans with } \\
\text { DFU/Neuropa } \\
\text { thic ulcer } \\
\text { (n=98)* }\end{array}$ \\
\hline $\begin{array}{l}\text { Age at first study } \\
\text { ulcer presentation }\end{array}$ & -- & $\begin{array}{l}\text { Mean } \\
(\mathrm{SE})\end{array}$ & 67 & 69 & 64 \\
\hline Sex & Male & $\%$ & 100 & 98 & 99 \\
\hline \multirow{3}{*}{ Race } & White & \multirow{3}{*}{$\%$} & 65 & 60 & 67 \\
\hline & African American & & 3 & 5 & 6 \\
\hline & Other & & 31 & 35 & 27 \\
\hline \multirow{14}{*}{$\begin{array}{l}\text { Medical history } \\
\text { (condition(s) } \\
\text { diagnosed before } \\
\text { ulcer onset) }\end{array}$} & Metabolic syndrome & \multirow{14}{*}{$\%$} & 71 & 61 & 82 \\
\hline & Diabetes & & 47 & 70 & 89 \\
\hline & Sensory neuropathy & & 33 & 70 & 85 \\
\hline & $\begin{array}{l}\text { Charcot } \\
\text { neuroarthropathy }\end{array}$ & & 0 & 0 & 6 \\
\hline & $\begin{array}{l}\text { Peripheral vascular } \\
\text { disease (PVD) }\end{array}$ & & 31 & 95 & 31 \\
\hline & Venous insufficiency & & 49 & 18 & 7 \\
\hline & Hypertension & & 83 & 89 & 85 \\
\hline & $\begin{array}{l}\text { Coronary artery disease } \\
\text { (CAD) }\end{array}$ & & 42 & 60 & 35 \\
\hline & $\begin{array}{l}\text { Myocardial infarction } \\
\text { (MI) }\end{array}$ & & 15 & 33 & 13 \\
\hline & $\begin{array}{l}\text { Congestive heart failure } \\
\text { (CHF) }\end{array}$ & & 31 & 37 & 20 \\
\hline & Cerebrovascular disease & & 10 & 33 & 17 \\
\hline & $\begin{array}{l}\text { Moderate or severe } \\
\text { renal disease }\end{array}$ & & 19 & 23 & 16 \\
\hline & Cancer & & 10 & 21 & 9 \\
\hline & $\begin{array}{l}\text { Immobility history } \\
\text { (current or former) }\end{array}$ & & 31 & 56 & 26 \\
\hline \multirow{4}{*}{ Lower limb history } & $\begin{array}{l}\text { Lower limb surgery } \\
\text { within } 60 \text { days }\end{array}$ & \multirow{4}{*}{$\%$} & 0 & 23 & 13 \\
\hline & $\begin{array}{l}\text { Traumatic lower limb } \\
\text { injury }\end{array}$ & & 20 & 11 & 17 \\
\hline & Prior lower limb ulcer & & 68 & 62 & 66 \\
\hline & Amputation & & 10 & 39 & 34 \\
\hline
\end{tabular}




\begin{tabular}{|c|c|c|c|c|c|c|}
\hline \multirow[b]{2}{*}{ 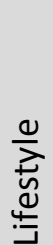 } & $\begin{array}{l}\text { Smoking } \\
\text { history }\end{array}$ & Current or former & $\%$ & 68 & 82 & 37 \\
\hline & $\begin{array}{l}\text { Body mass } \\
\text { index } \\
\text { (BMI) }\end{array}$ & $\begin{array}{l}\text { Baseline body mass } \\
\text { index }(\mathrm{BMI}) \geq 30.0\end{array}$ & $\%$ & 76 & 25 & 60 \\
\hline \multirow[b]{3}{*}{$\begin{array}{l}\text { d } \\
\frac{1}{2} \\
\frac{\pi}{3} \\
\frac{1}{0} \\
0 \\
\frac{0}{0} \\
0 \\
\frac{0}{0}\end{array}$} & $\begin{array}{l}\text { Hemoglobin } \\
\text { A1c }\end{array}$ & $\begin{array}{l}\text { Baseline }>7.0 \% \text { among } \\
\text { people with diabetes }\end{array}$ & $\%$ & 58 & 49 & 69 \\
\hline & $\begin{array}{l}\text { Serum } \\
\text { creatinine }\end{array}$ & Baseline $\geq 1.0$ & $\%$ & 67 & 37 & 70 \\
\hline & $\begin{array}{l}\text { Estimated } \\
\text { glomerular } \\
\text { filtration } \\
\text { rate } \\
\text { (eGFR) }\end{array}$ & Baseline $<60$ & $\%$ & 35 & 37 & 30 \\
\hline
\end{tabular}

*Veterans can fall into more than one ulcer etiology columns because 6 veterans had mixed arterial-venous ulcers and 3 veterans had mixed DFU-arterial ulcer 
Table 3. Chronic ulcer frequency and outcomes in VISN 20 Veterans at 12 months follow-up

\begin{tabular}{|l|c|c|c|}
\hline $\begin{array}{c}\text { Ulcer frequency and } \\
\text { outcomes }\end{array}$ & $\begin{array}{c}\text { Venous Ulcers } \\
\mathrm{N}=78\end{array}$ & $\begin{array}{c}\text { Arterial Ulcers } \\
\mathrm{N}=57\end{array}$ & $\begin{array}{c}\text { DFU/Neuropathic Ulcers } \\
\mathrm{N}=98\end{array}$ \\
\hline Healed $\mathbf{n}$ (\%) & $56(72)$ & $30(53)$ & $73(75)$ \\
\hline Amputated $\mathbf{n}$ (\%) & $1(1)$ & $13(23)$ & $3(15)$ \\
\hline Death $\mathbf{n}(\%)$ & $6(8)$ & $7(12)$ & $7(7)$ \\
\hline Unresolved $\mathbf{n}(\%)$ & $14(18)$ & $6(10)$ & $0(0)$ \\
\hline Loss to follow-up $\mathbf{n}(\%)$ & $1(1)$ & $1(2)$ & $3(0)$ \\
\hline
\end{tabular}


Table 4. Chronic ulcer healing and evidence-based ulcer care in VISN 20 Veterans

\begin{tabular}{|c|c|c|c|c|c|}
\hline $\begin{array}{l}\text { Ulcer Etiology } \\
\text { Model }\end{array}$ & Ulcer care component & $\begin{array}{c}\text { Percent } \\
\text { Veterans* }\end{array}$ & $\begin{array}{c}\text { Cox } \\
\text { Hazard } \\
\text { Ratio for } \\
\text { Healing } \\
\end{array}$ & $\begin{array}{c}95 \% \\
\text { Confidence } \\
\text { Interval }\end{array}$ & $P$ value \\
\hline \multirow{5}{*}{ Venous $(N=78) \dagger$} & Edema assessment at $\geq 80 \%$ of visits & 20 & 3.20 & $1.34-7.66$ & 0.009 \\
\hline & Moist wound healing at $\geq 80 \%$ of visits & 20 & 0.50 & $0.18-1.42$ & 1.192 \\
\hline & Infection assessment at $\geq 80 \%$ of visits & 23 & 3.54 & $1.42-8.79$ & 0.006 \\
\hline & $\begin{array}{l}\text { Percent visits with edema treated when } \\
\text { edema was present }\end{array}$ & & 1.00 & $0.99-1.01$ & 0.907 \\
\hline & Sharp debridement at $\geq 80 \%$ of visits & 0 & & & \\
\hline \multirow{3}{*}{ Arterial $(\mathrm{N}=57) \ddagger$} & Ischemia assessment at $1^{\text {st }}$ visit & 56 & 1.40 & $0.57-3.28$ & 0.489 \\
\hline & $\begin{array}{l}\text { Encounter with vascular surgery within } \\
30 \text { days of ulcer onset }\end{array}$ & 39 & 1.91 & $0.73-5.0$ & 0.191 \\
\hline & Infection assessment at $\geq 80 \%$ of visits & 32 & 2.10 & $0.80-5.43$ & 0.135 \\
\hline \multirow{5}{*}{$\begin{array}{l}\text { DFU/Neuropathic } \\
(\mathrm{N}=98) \S\end{array}$} & Debridement at $\geq 80 \%$ of visits & 19 & 2.50 & $1.1-5.8$ & 0.032 \\
\hline & Moist wound healing at $\geq 80 \%$ of visits & 19 & 0.65 & $0.28-1.5$ & 0.329 \\
\hline & Offloading at $\geq 80 \%$ of visits & 13 & 2.0 & $0.79-4.9$ & 0.144 \\
\hline & Ischemia assessed at $1^{\text {st }}$ visit & 50 & 2.0 & $1.0-3.9$ & 0.045 \\
\hline & Infection assessed at $\geq 80 \%$ of visits & 51 & 0.80 & $0.41-1.6$ & 0.509 \\
\hline
\end{tabular}

*Percent Veterans with the specific ulcer etiology for whom listed component of ulcer care was achieved

† Model also included: rural status; age at first study ulcer presentation; smoking status; and history of PVD, CAD, diabetes, lower limb ulcer, lower limb amputation, and moderate to severe renal disease.

¥ Model also included: rural status; age at first study ulcer presentation; smoking status; and history of CAD, diabetes, lower limb ulcer, lower limb amputation, and moderate to severe renal disease.

§Model also included: rural status; age at first study ulcer presentation; smoking status; and history of PVD, CAD, lower limb ulcer, lower limb amputation, and moderate to severe renal disease. 


\section{Conclusion and future recommendation}

Chronic wounds have a considerable impact on morbidity, mortality, and quality of life, and therefore should receive high quality evidence based wound treatment. However, partly due to the overwhelming amount of literature with often conflicting results, treatment decisions are generally based on personal opinion and provider preference. ${ }^{33}$ The body of evidence on individual components of care to treat major chronic ulcer etiologies is substantial (Table 1). However, the impact of combinations of these wound care components on ulcer healing has rarely been investigated. Originally the goal of this research project was to combine components of etiology specific ulcer care in one 'evidence-based good ulcer care' variable, and to investigate the effect of such variable performed in at least $80 \%$ of visits on time to healing. The components of good care for each ulcer etiology are listed in Table 1. Preliminary examination of data however revealed that very few Veterans received all components of EB wound care in at least $80 \%$ of their visits. This finding was consistent among all three ulcer etiologies. Since creating a good ulcer care variable was not reasonable, we decided to examine the effect of each ulcer care component on time to healing, while adjusting for health history variables and other wound care components (Table 4).

Another objective of this study was to investigate the impact of specialty care on ulcer healing. We did not find any significant difference in healing time in patients who received specialty care within one months of ulcer onset as compared to those who did not (Table 5). We then computed the proportion of ulcer care visits for each etiology that was performed by specialists, primary care providers, wound care nurses, and general nurses (Table 6).

In order to explore the quality of EB ulcer care performed by each provider type, we computed how often each type of provider performed components of EB ulcer care (Table 7). Among Veterans with venous ulcers, vascular surgery followed by combination of orthopedics, dermatology, and general surgery provided the highest level of edema treatment ( $93 \%$ and $86 \%$ of visits, respectively). Wound- 
care providers followed by specialty care (orthopedics, dermatology, and general surgery) performed moist wound healing most frequently. Veterans with DFU/neuropathic ulcers received overall better ulcer care from podiatry, which performed sharp debridement at $69 \%$ of visits, offloading at $54 \%$ of visits, and moist wound healing at $49 \%$ of visits. Wound-care providers however performed moist wound healing at a higher proportion of visits compared to podiatry (82\%). Vascular surgery, podiatry, and urgent care providers assessed for ulcer infections more often that did other provider types.

We further investigated the relationship between diabetes control and time to healing across all three ulcer types. Adequate diabetes control was defined as A1C value $<7.0$. We did not see any significant association between diabetes control and ulcer healing. Results are shown in Table 8. There were no statistically significant findings by A1C across any of the ulcer groups.

Future prospective studies with larger sample size are needed to assess the impact of guideline concordance ulcer care on healing. Our parent study included 320 Veterans with chronic ulcers of all etiologies, however only 224 of these had etiology of interest for this study. Future studies should screen ulcers by etiology and only include ulcers with etiology of interest. Considering that most Veterans in our study did not receive guideline concordant care at majority of their visits, a prospective study can help improve this limitation by requiring that providers assess for and perform all EB ulcer care components at appropriate intervals if clinically applicable. A prospective study could also improve the quality of the provider progress notes. For example an etiology specific ulcer care standardized template could greatly improve patient care as well as improve data quality for research. 
Table 5. Receipt of specialty care by one month following presentation and time to healing for chronic ulcers in VISN 20 Veterans

\begin{tabular}{|c|c|c|c|c|c|}
\hline $\begin{array}{l}\text { Ulcer Etiology and specialty } \\
\text { type considered }\end{array}$ & $\begin{array}{l}\text { Median days } \\
\text { to heal with } \\
\text { specialty visit } \\
\text { by } 1 \text { month }\end{array}$ & $\begin{array}{l}\text { Median days to } \\
\text { heal with no } \\
\text { specialty visit } \\
\text { by } 1 \text { month }\end{array}$ & $\begin{array}{l}\text { Cox HR for } \\
\text { specialty visit } \\
\text { by } 1 \text { month }\end{array}$ & $\begin{array}{c}95 \% \\
\text { Confidence } \\
\text { Interval }\end{array}$ & $P$ value \\
\hline $\begin{array}{l}\text { Venous }(n=78) \\
\text { Specialty: vascular surgery, } \\
\text { orthopedics, dermatology }\end{array}$ & 118 & 127 & 0.58 & $0.24-1.37$ & 0.210 \\
\hline $\begin{array}{c}\text { Arterial }(n=57) \\
\text { Specialty: vascular surgery }\end{array}$ & 159 & 159 & 2.26 & $.91-5.64$ & 0.081 \\
\hline $\begin{array}{l}\text { DFU/Neuropathic }(n=98) \\
\text { Specialty: podiatry }\end{array}$ & 110 & 130 & 0.99 & $0.58-1.66$ & 0.950 \\
\hline $\begin{array}{c}\text { DFU/Neuropathic ( } n=98) \\
\text { Specialty: Dermatology, } \\
\text { orthopedics, vascular surgery }\end{array}$ & 116 & 127 & 1.20 & $0.57-2.56$ & 0.630 \\
\hline
\end{tabular}


Table 6. Proportion of wound care visits by provider type in VA VISN 20 Veterans

\begin{tabular}{|c|c|c|c|c|c|c|c|}
\hline Ulcer Etiology & $\begin{array}{l}\text { Proportion of } \\
\text { visits by } \\
\text { vascular } \\
\text { surgery }\end{array}$ & $\begin{array}{c}\text { Proportion } \\
\text { of visits by } \\
\text { specialty } \\
\text { care } \\
\text { (orthopedics, } \\
\text { dermatology, } \\
\text { general } \\
\text { surgery) }\end{array}$ & $\begin{array}{c}\text { Proportion of } \\
\text { visits by } \\
\text { podiatry }\end{array}$ & $\begin{array}{c}\text { Proportion of } \\
\text { visits by } \\
\text { primary care }\end{array}$ & $\begin{array}{l}\text { Proportion } \\
\text { of visits by } \\
\text { urgent care }\end{array}$ & $\begin{array}{c}\text { Proportion } \\
\text { of visits by } \\
\text { wound care } \\
\text { provider }\end{array}$ & $\begin{array}{c}\text { Proportion } \\
\text { of visits by } \\
\text { general } \\
\text { nursing }\end{array}$ \\
\hline Venous & $8 \%$ & $32 \%$ & $0.5 \%$ & $23 \%$ & $6 \%$ & $37 \%$ & $39 \%$ \\
\hline Arterial & $14 \%$ & $37 \%$ & $8 \%$ & $17 \%$ & $8 \%$ & $26 \%$ & $29 \%$ \\
\hline DFU/Neuropathic & $5 \%$ & $17 \%$ & $43 \%$ & $19 \%$ & $6 \%$ & $17 \%$ & $29 \%$ \\
\hline
\end{tabular}

*Percentage of visits for each ulcer type exceed $100 \%$ because veterans were seen by multiple providers in one day 
Table 7. Provider type evidence-based chronic ulcer care in VISN 20 Veterans

\begin{tabular}{|c|c|c|c|c|c|c|c|c|}
\hline \multicolumn{2}{|c|}{$\begin{array}{c}\text { Ulcer type and wound care } \\
\text { element }\end{array}$} & $\begin{array}{c}\text { Percent* } \\
\text { visits by } \\
\text { vascular } \\
\text { surgery }\end{array}$ & $\begin{array}{l}\text { Percent of } \\
\text { visits by } \\
\text { podiatry** }\end{array}$ & $\begin{array}{c}\text { Percent of } \\
\text { visits by } \\
\text { wound care }\end{array}$ & $\begin{array}{l}\text { Percent of visits by } \\
\text { 'specialty' } \\
\text { (Vascular surgery, } \\
\text { dermatology, } \\
\text { orthopedics) }\end{array}$ & $\begin{array}{l}\text { Percent of } \\
\text { visits by } \\
\text { primary } \\
\text { care }\end{array}$ & $\begin{array}{l}\text { Percent of } \\
\text { visits by } \\
\text { nursing }\end{array}$ & $\begin{array}{l}\text { Percent of } \\
\text { visits by } \\
\text { urgent care }\end{array}$ \\
\hline \multirow{4}{*}{ Venous } & $\begin{array}{c}\text { Edema } \\
\text { assessment }\end{array}$ & 38 & & 37 & 31 & 53 & 43 & 49 \\
\hline & $\begin{array}{c}\text { Edema } \\
\text { treatment }\end{array}$ & 93 & & 71 & 86 & 44 & 53 & 56 \\
\hline & $\begin{array}{l}\text { Moist wound } \\
\text { healing }\end{array}$ & 5 & & 59 & 55 & 37 & 46 & 53 \\
\hline & $\begin{array}{c}\text { Infection } \\
\text { assessment }\end{array}$ & 62 & & 59 & 52 & 54 & 50 & 74 \\
\hline Arterial & $\begin{array}{l}\text { Infection } \\
\text { assessment }\end{array}$ & 80 & 90 & 74 & 55 & 42 & 63 & 68 \\
\hline \multirow{4}{*}{$\begin{array}{c}\text { DFU/ } \\
\text { Neuropathic }\end{array}$} & $\begin{array}{c}\text { Sharp } \\
\text { debridement }\end{array}$ & 19 & 69 & 54 & 16 & 16 & 18 & 22 \\
\hline & $\begin{array}{l}\text { Moist wound } \\
\text { healing }\end{array}$ & 22 & 49 & 82 & 29 & 25 & 49 & 14 \\
\hline & $\begin{array}{l}\text { Infection } \\
\text { assessment }\end{array}$ & 94 & 91 & 64 & 61 & 58 & 56 & 86 \\
\hline & Offloading & 22 & 54 & 40 & 27 & 18 & 24 & 16 \\
\hline
\end{tabular}

*Percent total visits by each provider type with element of wound care performed

**Venous ulcer visits by 'podiatry' are too few for this analysis 
Table 8. Diabetes control and chronic ulcer time to healing in VISN 20 Veterans with diabetes

\begin{tabular}{|c|c|c|c|c|}
\hline \multirow{2}{*}{ Ulcer type } & $\begin{array}{c}\text { A1C level at baseline (within } \\
\mathbf{6} \text { months of ulcer onset) }\end{array}$ & Cox Hazard Ratio & $\begin{array}{c}\text { 95\% Confidence } \\
\text { Interval }\end{array}$ & P Value \\
\hline \multirow{3}{*}{ Arterial } & $<7.0^{*}$ & 0.61 & $0.19-1.96$ & 0.405 \\
\cline { 2 - 5 } & $>7.0$ & 0.38 & $0.10-1.42$ & 0.099 \\
\hline \multirow{3}{*}{ DFU/Neuropathic } & $<7.0^{* *}$ & 1.0 & & 0.133 \\
\cline { 2 - 5 } & (Reference) & 0.65 & $0.37-1.14$ & 0.683 \\
\hline \multirow{2}{*}{ Venous } & $>7.0$ & 0.76 & $0.21-2.77$ & 0.131 \\
\cline { 2 - 5 } & $<7.0$ & 1.88 & $0.82-4.29$ & \\
\hline
\end{tabular}

*Reference group is veterans with no diabetes

** The reference group is those with controlled diabetes $(\mathrm{A} 1 \mathrm{C}<7.0)$ 


\section{Bibliography}

1. Hopf HW, Ueno C, Aslam R, et al. Guidelines for the treatment of arterial insufficiency ulcers. Wound Repair Regen. 2006;14:693-710.

2. Steed DL, Attinger C, Colaizzi T, et al. Guidelines for the treatment of diabetic ulcers. Wound Repair Regen. 2006;14:680-692.

3. Robson MC, Cooper DM, Aslam R, Gould LJ, Harding KG, Margolis DJ. Guidelines for the treatment of venous ulcers. Wound Repair Regen. 2006;14:649-662.

4. Pinzur M, Slovenkai M, Trepman E, Shields N. Diabetes committee of american orthopaedic foot and ankle society. Guidelines for diabetic foot care: Recommendations endorsed by the diabetes committee of the american orthopaedic foot and ankle society. Foot Ankle Int. 2005;26:113-119.

5. Bonham PA. Assessment and management of patients with venous, arterial, and diabetic/neuropathic lower extremity wounds. AACN Clinical Issues. 2003;14(2):442-456.

6. Olson JM, Raugi GJ, Nguyen VQ, Yu O, Reiber GE. Guideline concordant venous ulcer care predicts healing in a tertiary care veterans affairs medical center. Wound Repair Regen. Sep-Oct 2009;17(5):666-670.

7. Spentzouris G, Labropoulos N. The evaluation of lower-extremity ulcers. Semin Intervent Radiol. Dec 2009;26(4):286-295.

8. Smith DG, Michael JW, Bowker J. Atlas of amputations and limb deficiencies 3ed: Amer Academy of Orthopaedic; 2004.

9. Mayfield JA, Reiber GE, Maynard C, Czerniecki J, Sangeorzan B. The epidemiology of lowerextremity disease in veterans with diabetes Diabetes Care. 2004;27(Suppl. 2):B39-B44.

10. Edwards H, Finlayson K, Courtney M, Graves N, Gibb M, Parker C. Health service pathways for patients with chronic leg ulcers: Identifying effective pathways for facilitation of evidence based wound care. BMC Health Services Research. 2013;13(86).

11. Bulbulia R, Poskitt K. The need for a national service framework for leg ulcers. Phlebology. 2010;25(Suppl. 1):68-72.

12. Inc AWMAIaNZWCS. Australian and new zealand clinical practice guideline for prevention and management of venous leg ulcers. Cambridge Publishing. 2011.

13. (SIGN) SIGN. Management of chronic venous leg ulcers. A national clinical guideline. 2010;Edinburgh(SIGN).

14. Margolis DJ, Allen-Taylor L, Hoffstad O, Berlin JA. Diabetic neuropathic foot ulcers- the association of wound size, wound duration, and wound grade on healing. Diabetes Care. 2002;25:1835-1839.

15. Ince P, Game FL, Jeffcoate WJ. Rate of healing of neuropathic ulcers of the foot in diabetes and its relationship to ulcer duration and ulcer area. Diabetes Care. Mar 2007;30(3):660-663.

16. Lowe JR, Raugi GJ, Reiber GE, Whitney JD. Does incorporation of a clinical support template in the electronic medical record improve capture of wound care data in a cohort of veterans with diabetic foot ulcers? J Wound Ostomy Continence Nurs. Mar 2013;40(2):157-162.

17. Tatsioni A, Balk E, O'Donnell T, Lau J. Usual care in the management of chronic wounds- a review of the recent literature. Journal of American College of Surgeons. 2007;205(4):617-624.

18. The united states census bureau, u.S department of commerce. "Urban and rural classification". . http://www.census.gov/geo/reference/urban-rural.html. Accessed July 27, 2013.

19. Sewitch M, Blais R, Rahme E, Bexton B, Galarneau S. Receiving guideline-concordant pharmacotherapy for major depression- impact on ambulatory and inpatient health service use. Canadian Journal of Psychiatry. 2007;52(3):191-200. 
20. Allen LA, O'Donnell CJ, Giugliano RP, Camargo CA, Jr., Lloyd-Jones DM. Care concordant with guidelines predicts decreased long-term mortality in patients with unstable angina pectoris and non-st-elevation myocardial infarction. Am J Cardiol. May 15 2004;93(10):1218-1222.

21. Raju S, Hollis K, Neglen P. Use of compression stockings in chronic venous disease: Patient compliance and efficacy. Ann Vasc Surg. Nov 2007;21(6):790-795.

22. Svensjö T, Pomahac B, Yao F, Slama J, Eriksson E. Accelerated healing of full-thickness skin wounds in a wet environment. Plast Reconstr Surg. 2000;106(3):602-612.

23. Vranckx J, Slama J, Preuss S, et al. Wet wound healing. Plast Reconstr Surg. 2002;110:1680-1687.

24. Eaglstein W. Moist wound healing with occlusive dressings - a clinical focus. Dermatology Surg. 2001;27:175-181.

25. Game FL, Hinchliffe RJ, Apelqvist J, et al. A systematic review of interventions to enhance the healing of chronic ulcers of the foot in diabetes. Diabetes Metab Res Rev. Feb 2012;28 Suppl 1:119-141.

26. WB W, LE K, Y S, et al. Differences in health-related quality of life in rural and urban veterans. Am J Public Health. 2004;94(10):1762-1767.

27. Health DoVAOoR. Rural health day fact sheet http://www.ruralhealth.va.gov/docs/ORH FactSheet Natl Rural Health Day Nov2011.pdf. Accessed 06/27/13.

28. Collins L, Seraj S. Diagnosis and treatment of venous ulcers. American Family Physician. April 15 2010;81(8):989-996.

29. de Araujo T, Valencia I, Federman D, Kirsner R. Managing the patient with venous ulcers. Ann Intern Med. Feb 18 2003;138(4):326-334.

30. Phillips T, Machado F, Trout R, Porter J, Olin J, Falanga V. Prognostic indicators in venous ulcers. J Am Acad Dermatol. Oct 2000;43(4):627-630.

31. London NJ, Donnelly R. Abc of arterial and venous disease. Ulcerated lower limb. BMJ. June 10 2000;320(7249):1589-1591.

32. Junker J, Caterson E, Eriksson E. The microenvironment of wound healing. J Craniofaciac Surg. 2013;24(1):12-16.

33. Brolmann FE, Ubbink DT, Nelson EA, Munte K, van der Horst CM, Vermeulen H. Evidence-based decisions for local and systemic wound care. Br J Surg. Sep 2012;99(9):1172-1183.

34. O'Meara S, Cullum N, Nelson E. Compression for venous leg ulcers. Cochrane Database Syst Rev. 2009.

35. Cardinal M, Eisenbud DE, Armstrong DG, et al. Serial surgical debridement: A retrospective study on clinical outcomes in chronic lower extremity wounds. Wound Repair Regen. 2009;17(3):306311.

36. Schultz G, Sibbald R, Falanga V, et al. Wound bed preparation: A systematic approach to wound management. Wound Repair Regen. Mar 2003;11(Suppl 1):S1-28.

37. Mohler El. Peripheral arterial disease: Identification and implications. Arch Intern Med. Oct 27 2003;163(19):2306-2314.

38. Teodorescu VJ, Chen C, Morrissey N, Faries PL, Marin ML, Hollier LH. Detailed protocol of ischemia and the use of noninvasive vascular laboratory testing in diabetic foot ulcers. The American Journal of Surgery. 2004;187(5):S75-S80.

39. Hirsch AT, Haskal ZJ, Hertzer NR, et al. Acc/aha 2005 practice guidelines for the management of patients with peripheral arterial disease (lower extremity, renal, mesenteric, and abdominal aortic): A collaborative report from the american association for vascular surgery/society for vascular surgery, society for cardiovascular angiography and interventions, society for vascular medicine and biology, society of interventional radiology, and the acc/aha task force on practice guidelines (writing committee to develop guidelines for the management of patients with 
peripheral arterial disease): Endorsed by the american association of cardiovascular and pulmonary rehabilitation; national heart, lung, and blood institute; society for vascular nursing; transatlantic inter-society consensus; and vascular disease foundation. Circulation.

2006;113(11):463-654.

40. Hirsch AT, Criqui MH, Treat-Jacobson D, et al. Peripheral arterial disease detection, awareness, and treatment in primary care. JAMA. Sep 19 2001;286(11):1317-1324.

41. Armstrong DG, Nguyen HC, Lavery LA, Van Schie CH, Boulton AJ, Harkless LB. Off-loading the diabetic foot wound: A randomized clinical trial. Diabetes Care. 2001;24:1019-1022.

42. Steed $D$, Donohoe $D$, Webster $M$, Lindsley $L$. Effect of extensive debridement and treatment on the healing of diabetic foot ulcers. Diabetic ulcer study group. J Am Coll Surg. 1996;183(1):61-64.

43. Bradley M, Cullum N, Sheldon T. The debridement of chronic wounds: A systematic review. Health Technol Assess. 1999;3:1-78.

44. Jeffcoate WJ. Wound healing - a practical algorithm. Diabetes Metab Res Rev. 2012;28 Suppl 1:85-88.

45. Whitney J, Phillips L, Aslam R, et al. Guidelines for the treatment of pressure ulcers. Wound Repair Regen. 2006;14:663-679. 
Appendix 


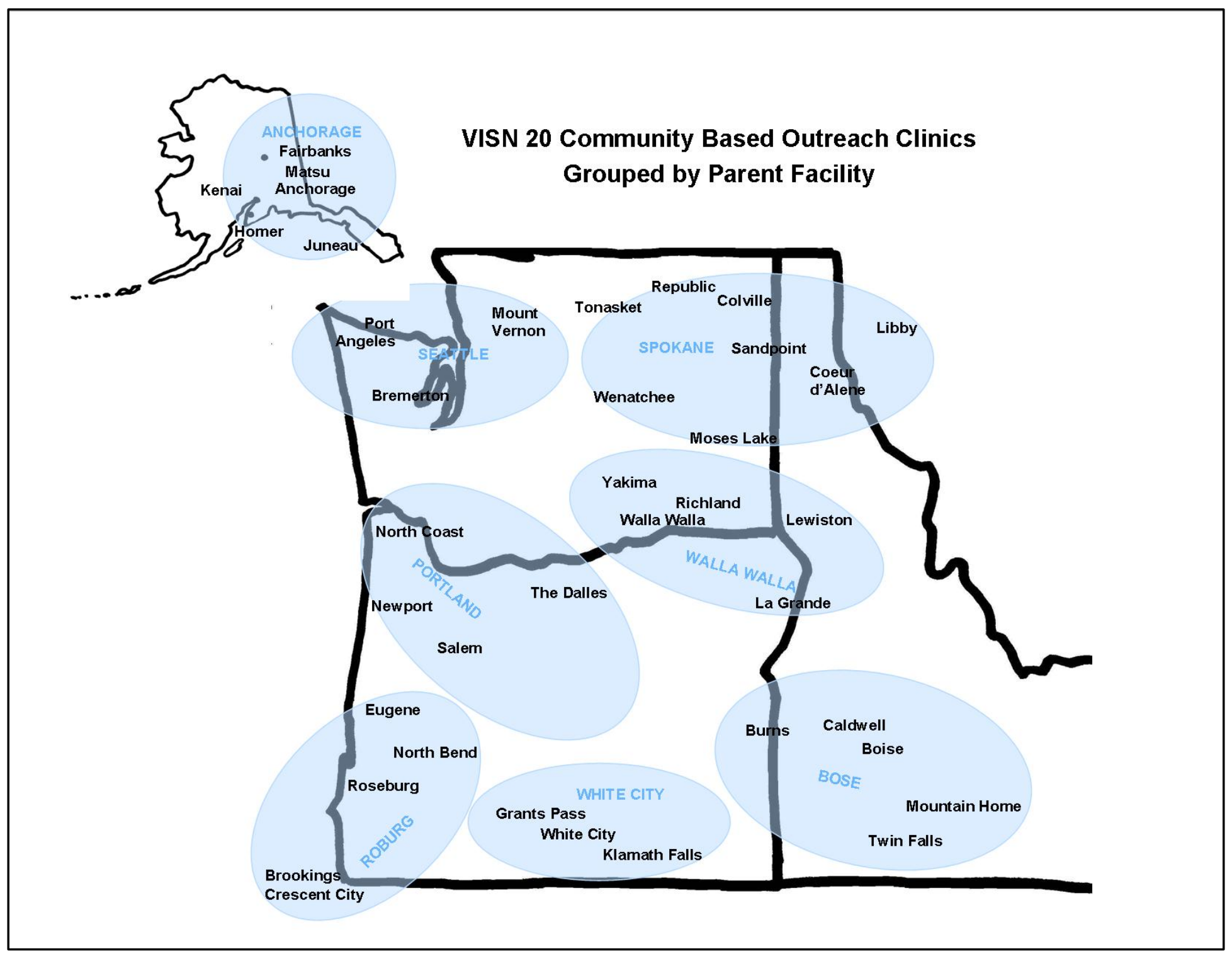




\section{Appendix B: Methods for assigning ulcer etiology}

In determining the cause of an ulcer (etiology), it is important to consider ICD-9 codes in conjunction with clinical details since codes may be inappropriately or inadequately applied and because of potential inconsistencies across providers. In this study, we considered the ICD codes recorded by specialist providers to be more reliable than those provided by primary care, urgent care, or other nonspecialty physicians (e.g., podiatrists or wound care nurses). We considered specific codes - those other than simple 707 codes - to be reliable when they were consistently provided across the course of an ulcer especially if coded by a specialist. In the absence of specialist codes or consistent, specific ICD codes, we reviewed progress notes and patient history to determine etiology. The decision tree below represents this process graphically:

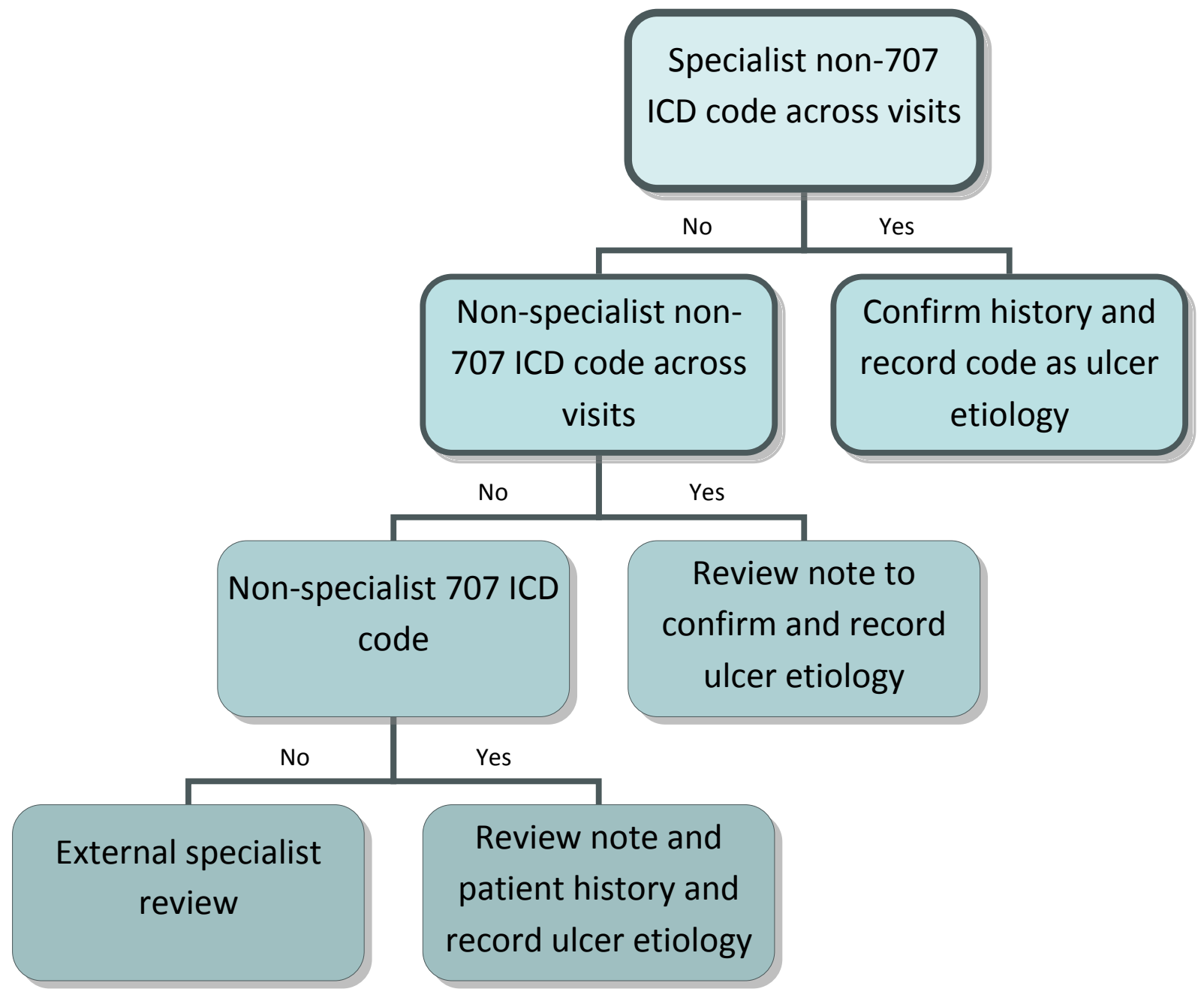

In reviewing the medical record and patient health history to determine ulcer etiology, we will consider the location of the ulcer, the concurrent medical conditions, and the history of ulceration.

\section{Diabetic ulcer etiology}

In general, diabetic ulcers occur on the plantar foot, below the level of the malleolus. In a patient with diabetes and neuropathy plantar foot ulcers are likely to be diabetic foot ulcers. Typically, neuropathy 
will be present while edema and ischemia will be absent. An ICD-9 code of 250.8/707or both codes individually listed within a single encounter are likely to indicate diabetic etiology in the absence of PVD.

There are diabetic patients who have foot ulcer and also suffer from severe peripheral arterial disease. In these cases, if there was strong evidence of arterial insufficiency preventing ulcer healing, the ulcer was classified as "arterial". Strong evidence consisted of 1-vascular surgeon note indicating that arterial insufficiency is preventing healing 2- if no vascular surgery note was present then ulcer was considered arterial only if ABI was $<0.6$ AND no pedal pulses were present AND a provider diagnosed the lesion as arterial ulcer and not DFU. In cases with suspected arterial insufficiency and lack of evidence for arterial disease, foot ulcers in a diabetic patient were classified as DFU.

Arterial ulcer etiology

Arterial ulcers typically occur on trauma prone areas of the foot and the level of the ankle or higher in the absence of venous insufficiency or edema. ICD-9 codes $443,440.9$, and 440.24 are likely to indicate an arterial ulcer. The patient's medical record is reviewed for foot exams confirming absent to no pulse as well as $A B I$ recordings of 0.8 or less on the affected leg. If patient has signs of arterial insufficiency in conjunction with signs of venous disease (edema, skin venous stasis changes, varicose veins) then specialty notes such as vascular surgery and dermatology notes are reviewed to assess relative contribution of each etiology to the chronic ulcer. If one etiology appears to dominate the non-healing process, then that etiology is selected as the study etiology. However, if two or more processes appear to be involved with unclear relative contributions, then ulcer etiology is labeled as "mixed" followed by the listing of each etiology suspected. When no specialty notes are available, physical exam and ABIs as well as ulcer location and patient history were used to make a clinical judgment on ulcer etiology. $A B I$ results superseded pedal pulse examination by providers in ruling out arterial disease unless specialty notes mentioned suspicion that $A B I$ was artificially elevated due to severe vascular disease.

\section{Venous ulcer etiology}

These ulcers typically occur at the level of the ankle or higher in patients who do not have arterial disease or diabetes and who do have edema. High likelihood codes for venous ulcers include ICD-9 codes 782, 459.31, and 459.81. Physical exam notes are reviewed to ensure presence of edema at the time of ulcer occurrence, as well as signs of sufficient arterial flow to rule out arterial etiology. Considering that assessment of pedal pulses is challenging in the setting of severe edema, multiple physical exam notes before and after ulcer occurrence and edema control were reviewed to ensure the presence of pedal pulse. If $A B I$ was $>0.8$ on the affected side, this result superseded pedal pulse examination by providers in ruling out arterial disease unless specialty notes mentioned a suspicion that $A B I$ was artificially elevated due to severe vascular disease. 


\section{Appendix C: Edema/ischemia assessment and presence}

The following flow diagrams demonstrate how we determined from provider progress notes whether edema/ischemia was assessed by the provider and whether edema/ischemia was present during visits.

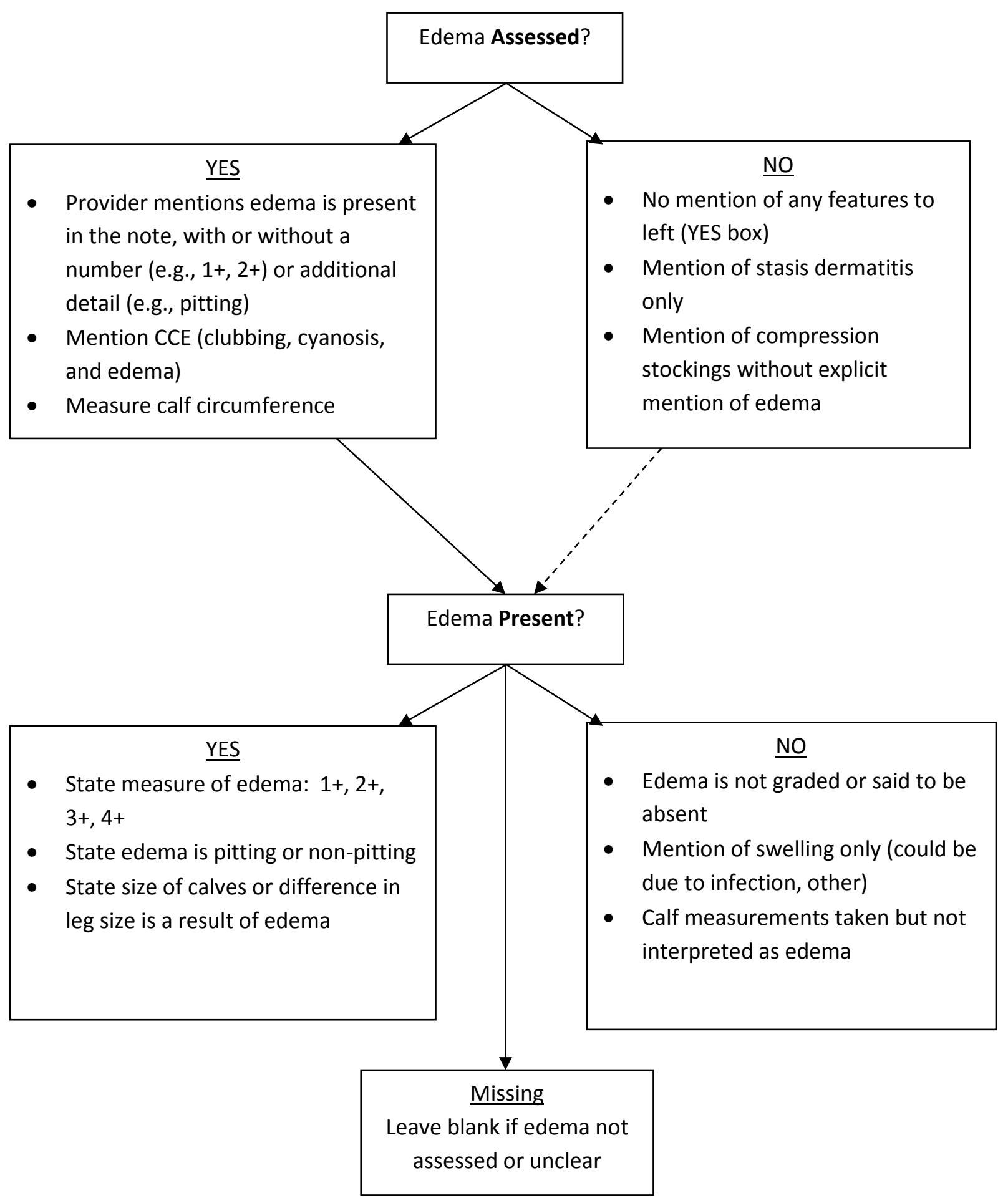




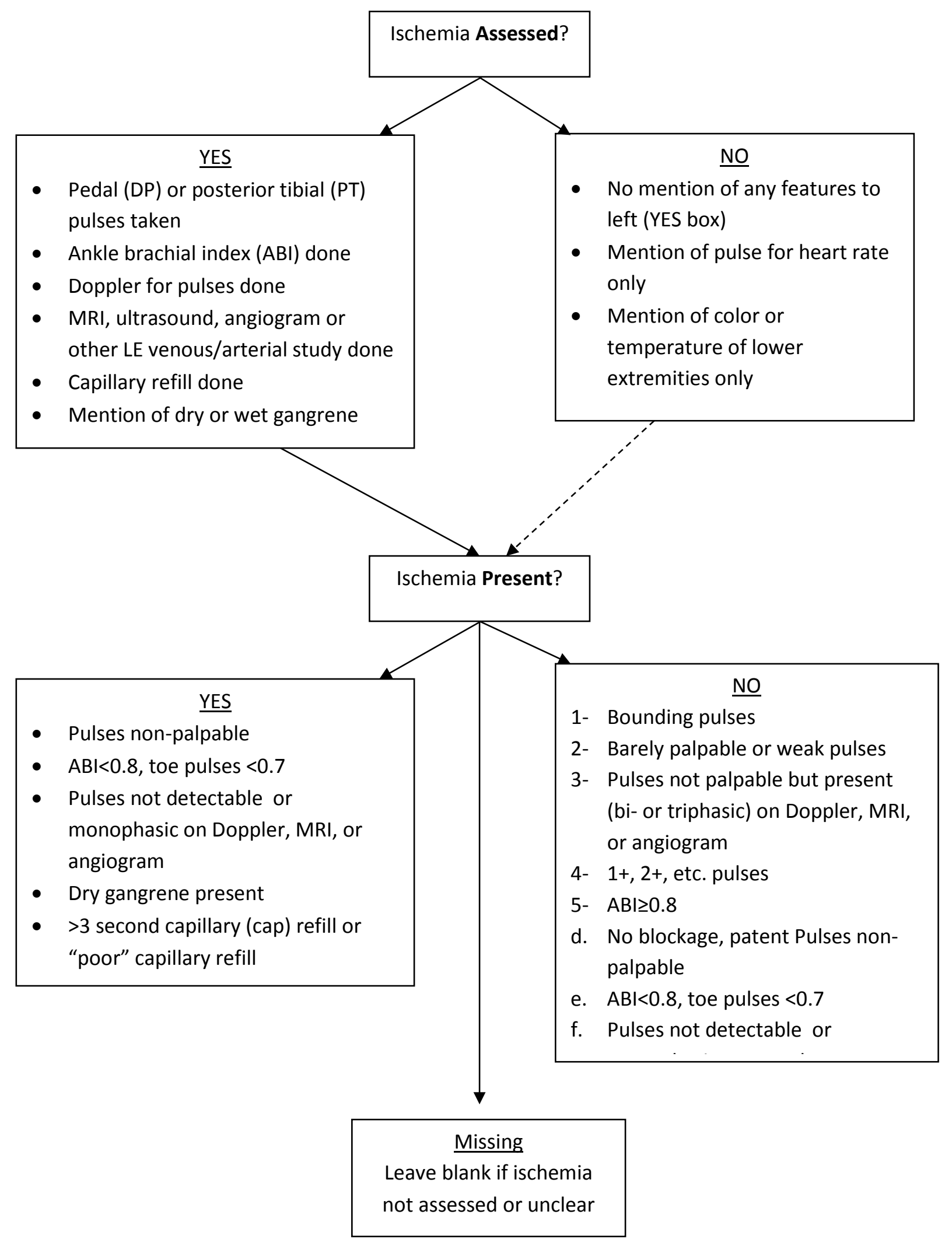


Appendix D: Moist wound healing

This is a list of moist dressings and wound medications used in this study:

\begin{tabular}{|l|l|}
\hline Acticoat & Oasis \\
Adaptic & Opsite \\
Alginate dressings & Panafil \\
Antimicrobial dressings & Polymax \\
Aquacel & Polymem \\
Aquaphor & Prisma \\
Calcicare & Promogran \\
Carrington wound gel & Regranex \\
Copa & Restore \\
Duoderm & Saf Gel \\
Fibracol & Silvadene \\
Foam & Silvercel \\
Honey & Sorbisan \\
Hydrocolloid dressings & Sugar paste \\
Hydrofera Blue & Tegaderm \\
Hydrosorb & Unna boot with calamine lotion \\
lodosorb & Unna boot (Unnapress) bandage \\
Kaltostat Cavity Dressing & Vaseline gauze \\
Lyofoam & Wound gel \\
Mepilex & Wound vac \\
Mepitel & Xeroform \\
\hline
\end{tabular}


|Baseline encounter: $1^{\text {st }}$ treatment date for incident ulcer 10/01/06 - 9/30/07 (mm- $d d-1 x)$
Study ID: ---

SSN \#:

Abstractor Initials:

\section{ACCESS TO CARE CHART ABSTRACTION} DEMOGRAPHICS

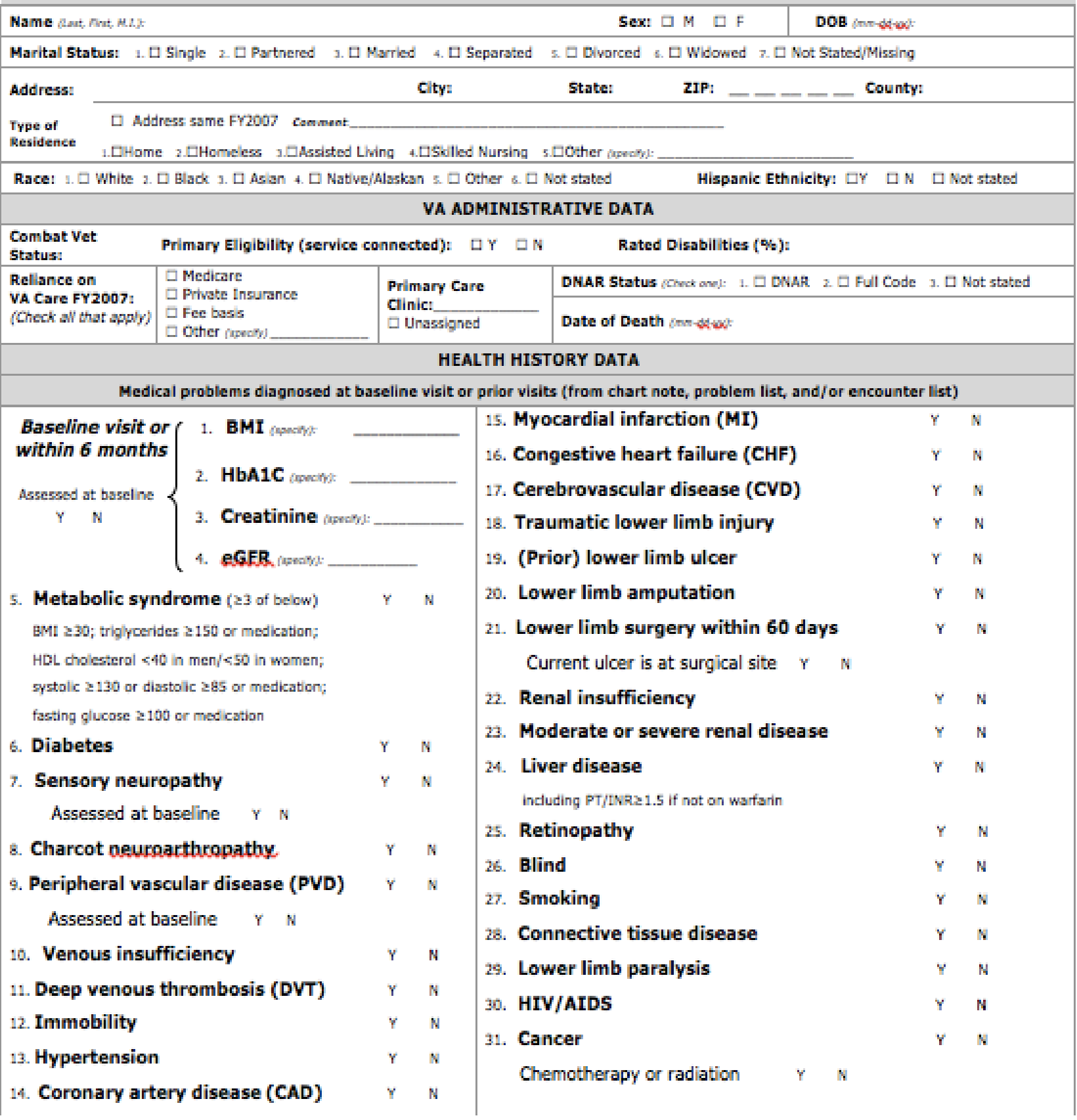




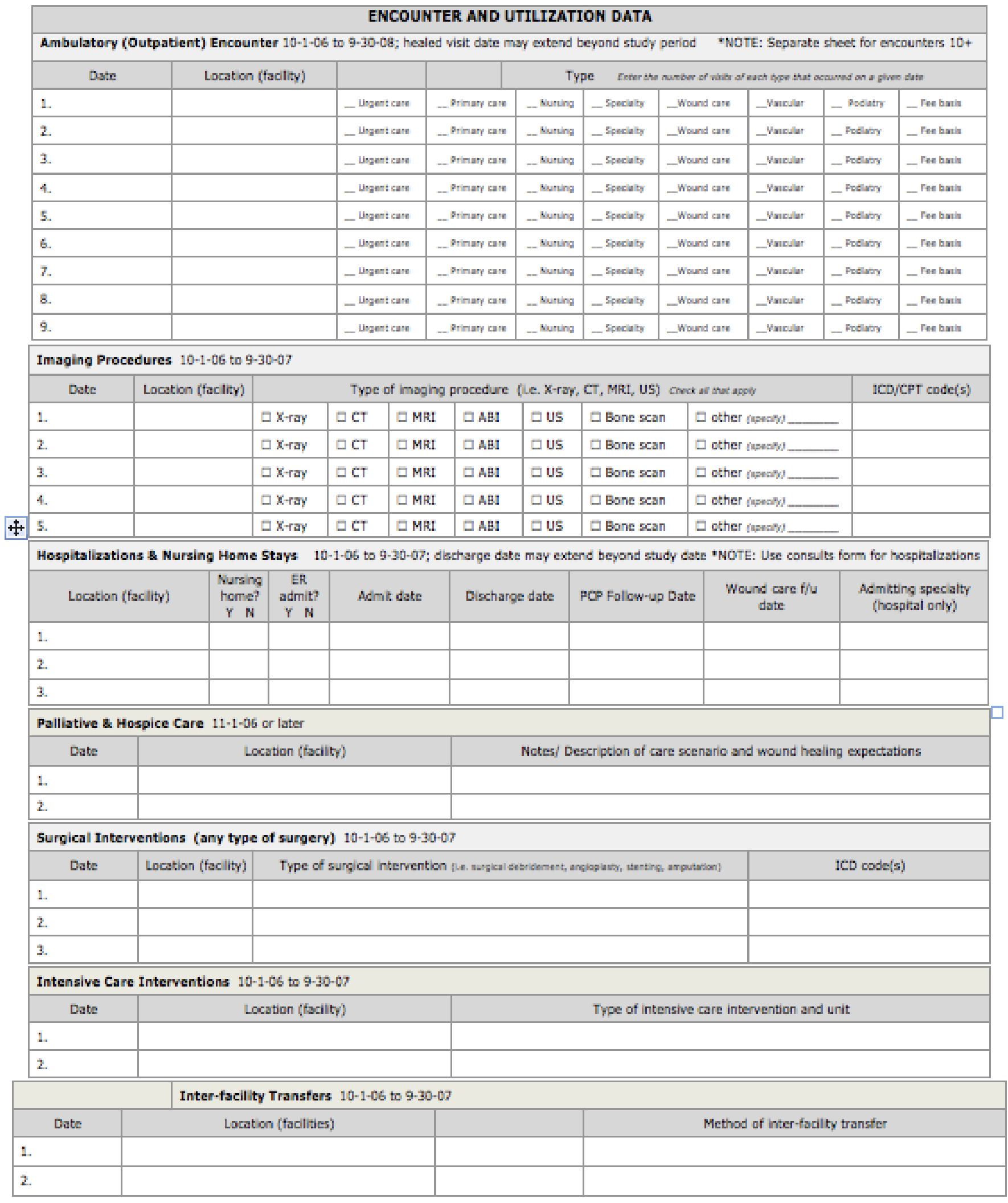




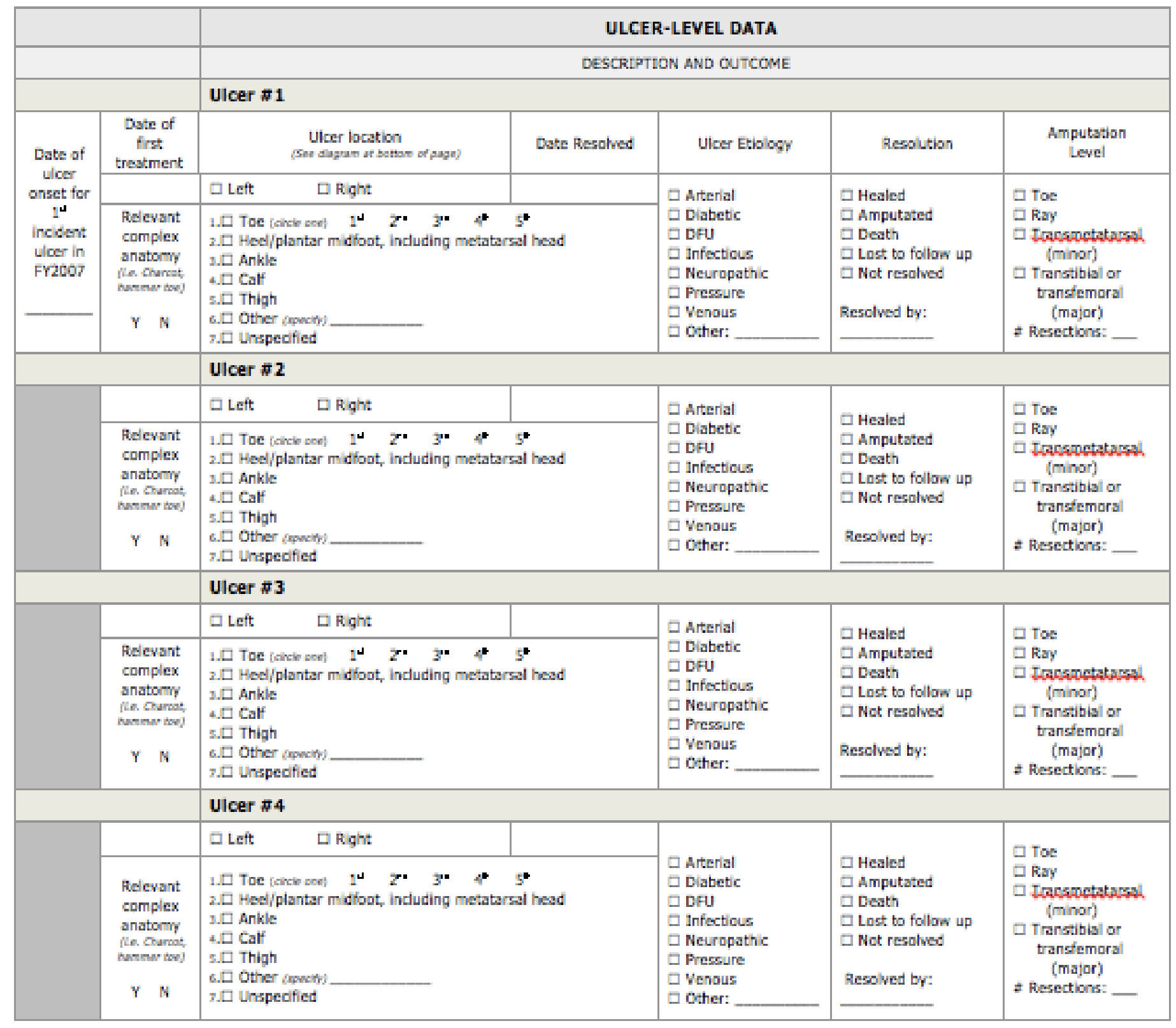

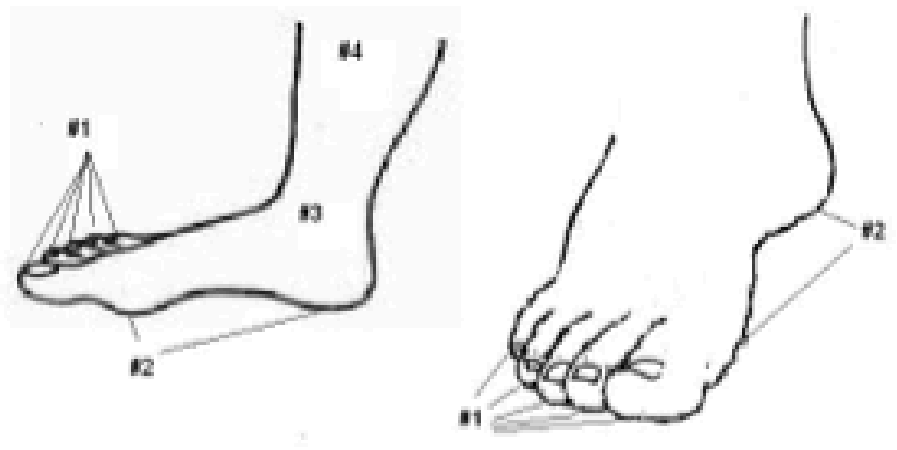




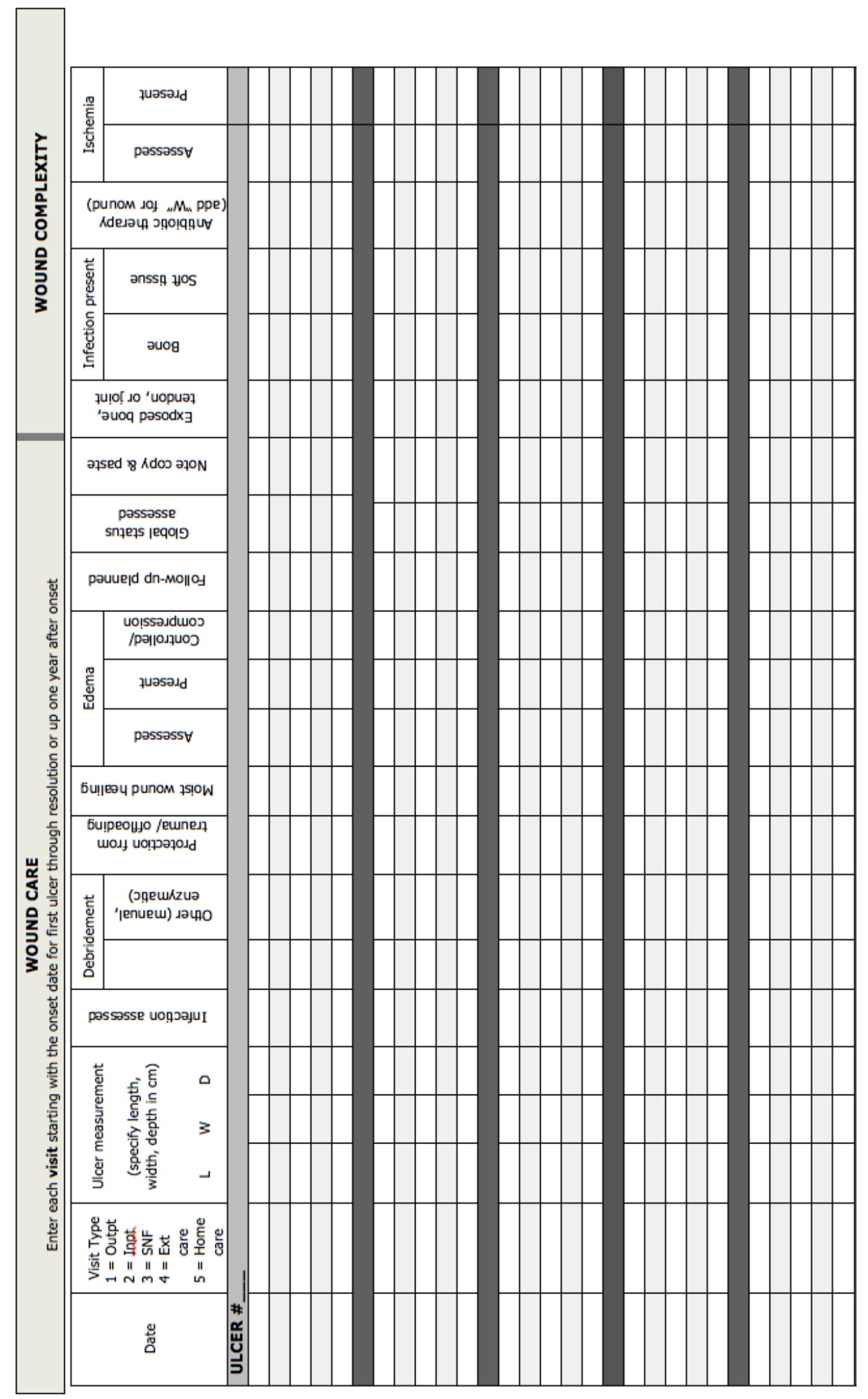

